Vierordt, Grundriss d. Physiologie d. Menschen, Tübingen 1877, S. 494.

Weber, in Wagner's Handwörterb. d. Physiologie, Braunschw. 1840, III. 2, S. $541 \mathrm{ff}$ u. $582 \mathrm{ff}$.

Weir Mitchell, Injuries of nerves, Philadelphia 1872, S. $353 \mathrm{ff}$.

Wernicke, Der aphasische Symptomencomplex, Berlin 1874, S. $5 \mathrm{ff}$.

Wundt, Beitr. z. Theorie d. Sinneswahrnehmung, Leipz. a. Heidelb. 1862, S. $400 \mathrm{ff}$.

- Vorlesungen üb. d. Menschen- u. Thierseele, Leipz. 1863, I, S. $220 \mathrm{ff}$.

- Grundzüge d. physiolog. Psychologie, Leipz. 1880, I, S. 372 ff.

(Aus dem physiologischen Institut zu Breslau.)

\title{
Wie die Muschel ihre Schaale öffnet.
}

Versuche und Fragen zur allgemeinen Muskel-und Nervenphysiologie.

Von

Dr. Joh. Pawlow,

Docenten an der medieinischen Akademie zu St. Petersburg.

Hierzu Tafel I.

Vorbemerkungen.

Die Untersuchung, deren Ergebnisse ich im Folgenden mittheile, war auf Anregung von Prof. Heidenhain ursprïnglich unternommen worden, um an dem Schliessmuskel von Anodonta thermophysiologische Beobachtungen anzustellen, welche bis jetzt an glatten Muskeln vollständig fehlen. Allein ich bin auf dem ursprünglich betretenen Wege nur so weit vorgeschritten, um feststellen zu können, dass bei der Zusammenziehung jenes Muskels merkliche Wärmeentwickelung statttindet. Zur Ermittelung ihrer Gesetze musste, wie sich bald herausstellte, eine Voruntersuchung über die verwickelten Innervationsverhältnisse des Muskels durchgeführt werden, welche meine gesammte disponible Zeit in An- 
spruch nahm, so dass die Weiterverfolgung der myothermischen Erscheinungen vorbehalten bleiben muss.

$\mathrm{Zu}$ den mitzutheilenden Versuchen wurden grosse Exemplare von Anodonta cygnea verwandt, im September gefangen und in hölzernen Wannen auf Sandboden unter mässig tiefer Wasserschicht den Winter über in einem ungeheizten Corridor des Instituts aufbewahrt. Zur Verhïtung von Verlusten ist täglicher Wasserwechsel erforderlich, dessen Vernachlässigung besonders dann schnell verderblich wirkt, wenn viele Thiere in demselben Behälter aufbewahrt werden. Bei sorgsamer Behandlung war kein wesentlicher Unterschied in dem Verhalten frisch eingefangener und lange aufbewahrter Exemplare bemerkbar. - Um bei der Beschreibung der Versuche die Gegenden des Thieres kurz bezeichnen zu können, bemerke ich Folgendes: die Seite des Thieres, an welcher die beiden Schaalen durch das Sehlossband verbunden sind, nenne ich die Rückenseite, die entgegengesetzte, an weleher die Schaalen auseinander klappen, die Bauchseite; das Mundende des Thieres das vordere, das entgegengesetzte Ende das hintere, dementsprechend die beiden Schliessmuskeln, den vordern und den hintern.

Im Vordertheile des Thieres, 6-8 $\mathrm{mm}$ von dem vordern Schliessmuskel entfernt, liegt jederseits unter dem Mantel ein Ganglion, welches mehrere Nervenzweige abgiebt: zu dem andersseitigen Ganglion, zu dem Muskel, zu dem Mantel, zu dem Ganglion des Fusses und endlich zu dem hintern, auf der Bauchseite des hintern Schliessmuskels gelegenen Ganglion. Letzteres steht also mit jedem der beiden vordern Ganglien durch einen Nerven in Verbindung; beide Nerven liegen in der Mitte ihres Verlaufes nahe aneinander. Ich werde sie als Verbindungsnerven bezeichnen. Das hintere Ganglion giebt ausserdem Zweige zu dem hintern Muskel, die aber, weil es demselben unmittelbar anliegt, sehr kurz sind, zum Mantel, zu den Kiemen a. s. f.

Die Präparation der Verbindungsnerven geschieht in folgender Weise. Nachdem ein ausreichender Theil derjenigen Schaale, welche bei den Versuchen nach oben gekehrt sein soll, mit Hülfe von Knochenzangen entfernt worden ist, sieht man nach der Rïckenseite des Thieres hin das Herz pulsiren. Nach Entfernung des Mantels und des Pericardiums wird das Herz exstirpirt und dadnreh das schwarz pigmentirte Bojanus'sche Organ freigelegt. 
Zwischen den Schläuchen desselben verlaufen die beiden Verbindungsnerven als weisse Fäden, die sich unschwer auf eine lange Strecke herauspräpariren, mittelst eines Fadens unterbinden und durchschneiden lassen, so dass sie vollkommen isolirt, nur zum Schutze gegen Austrocknung von ein wenig Gewebe eingehüllt, gereizt werden können.

Die Beobachtungen uiber die Bewegungsvorgänge an den Schliessmuskeln wurden zum allergrössten Theile mittelst eines einfachen graphischen Apparates angestellt, ähnlich demjenigen, welchen vor mehr als 20 Jahren A. Fick benutzte ${ }^{1}$ ). Auf einem Grundbrette steht eine verticale Messinghülse, in welcher eine Stahlstange verschiebbar ist. Letztere trägt einen sehr leichten zweiarmigen Hebel. Unterhalb seines kürzeren Armes worde die Muschel in eine passend geformte Aushöhlung des Brettes horizontal so gelagert, dass eine Schaale derselben in der Aushöhlung. durch eine eiserne Klammer befestigt war, während die nach oben gekehrte freie Schaale mittelst einer Seidenschnur mit dem kurzen Hebelarme in Verbindung stand. Der längere Hebelarm zeichnete mittelst einer beweglich an ihm aufgehängten Schreibnadel die Hebungen und Senkungen der Muschelschaale auf einem langsam rotirenden Baltzar'schen Kymographion auf. Nahe der Drehaxe war dieser Hebelarm mit einem in allen Versuchen gleichen, geringen Gewichte belastet. Die unten zu beschreibenden Präparate der Muschel wurden durch die bei der Präparation reichlich ausfliessende und in die fixirte Schaale gefällte Gewebsflüssigkeit feucht erhalten, das Schlossband durch einen nassen Fliesspapierbausch vor Austrocknung geschiitzt. In einer Anzahl von Versuchen wurde das Schlossband durch ein Messingeharnier ersetzt.

\section{§ 1. Einige Beobachtungen an dem unversehrten} Thiere.

Die unversehrte Muschel, längere Zeit im Wasser beobachtet, lässt in der Regel zeitweise spontane Bewegungen sehen: die Schaalen werden langsam ein wenig geöffnet und schneller wieder geschlossen. Mitunter treten die Bewegungen in fast regelmässigen Pausen ein. Ausserhalb des Wassers verktirzen sich die Intervalle.

1) A. Fick, Beiträge zur vergleichenden Physiologie der irritabeln Substanzen. Braunschweig 1863. 
In einem Falle z. B. zählten wir zwischen den einzelnen Contractionen an der Luft $8-9-7-61 / 2-51 / 2-31 / 2-3$ Minuten.

Diese Beschleunigung scheint dyspnoetischer Natur zu sein. Wenigstens werden die Schaalenbewegrngen auch innerhalb des Wassers häufiger, wenn Bedingungen einwirken, welche die Sauerstoffaufnahme von Aussen beschränken (z. B. wenn das Wasser ansgekocht oder mit Kohlensäure gesättigt ist) oder den Sauerstoffconsum im Körper steigern (z. B. bei höherer Temperatur des Wassers). So betrugen bei einem Exemplar die

Pausen zwischen den Bewegungen der Schaale:

In gewöhnlichem Wasser $\left(14-15^{0}\right.$ C. $) 5-7-8 \frac{1}{2}-5^{1 / 2}$ Minuten, in gekochtem und wieder abgekühltem

Wasser . . . . . . . . . 3-3-21/2-1-3-3 Minuten, darauf in gewöhnlichem Wasser . . $71 / 2^{1}-6^{1 / 2}-6-4-6-6$ Min., im Wasser von $18^{\circ} \mathrm{C}$. . . . . $1-2-2-2-1-1 \frac{1}{2}-2-2 \mathrm{Min}$., in gewöhnlichem Wasser . . . . 5-6-5 u. s. f. Minuten.

In warmem Wasser werden die Schaalen nicht blos häufiger, sondern auch weiter geöffnet, als in kühlem. Bei längerem Aufenthalt in der Wärme sinkt die Frequenz der Bewegungen wieder.

Es kam nun darauf an, die Centren und Nerven ausfindig zu machen, von welcher die Schliessung, beziehungsweise Oeffnung der Schaalen abhängt. $\mathrm{Zu}$ diesem Zwecke mussten die beiden Schliessmuskeln mit den zugehörigen Ganglien gesondert untersucht werden.

§2. Der hintere Schliessmuskel mit demzugehörigen Ganglion.

Zum Zwecke der folgenden Beobachtungen wurde ein Präparat hergestellt, welches aus dem hinteren Schliessmuskel mit den zugehörigen Stiicken der beiden Schaalen und des Schlossbandes, dem hintern Ganglion mit den Verbindungsnerven, und einem Stück des Mantels besteht, welches von dem Ganglion aus sensible Nervenfasern erhält. - Die Anfertigung dieses Präparates stösst für gewöhnlich auf Schwierigkeiten, weil mit dem Beginne der Präparation in Folge der unvermeidlichen sensiblen Reizungen der Schliessmuskel sich fester und fester reflectorisch contrahirt und nach Fertigstellung des Präparates ausserordentlich lange, 
selbst Tage lang, contrabirt bleibt. In diesem Zustande sind Versuche an dem Muskel natürlich unmöglich, wenn man nicht Mittel findet, die Contraction zu lösen.

Ein derartiges Mittel besteht in der vor Anfertigung des Präparates herbeizuftihrenden Narcose des Thieres durch Morphium. Nach Injection von 4-6 ccm einer zweiprocentigen Lösung von salzsaurem Morphium in den Fuss lassen sich die Schaalen in 10-20 Minuten leichter öffnen; noch später öffnen sie sich von selbst, und zwar in viel weiterem Umfange als bei den oben besprochenen spontanen Bewegungen. Injection von Kochsalzlösung statt des Morphiums hat keinen Einfluss, so dass es sich zweifellos um Narcose durch das Alcaloid, nicht etwa um mechanische Einwirkung der injicirten Fliissigkeit handelt. Haben die Schaalen sich geöffnet, so lässt sich das oben besprochene Präparat viel leichter anfertigen, als ohne vorgängige Narcose. Controllirt man jetzt das Verhalten des Muskels mittelst des graphischen Apparates, so stellt sich Folgendes heraus.

Der Muskel macht periodische Contractionen, deren Curve (vgl. Fig. 1) an Gestalt der Zuckungscurve eines quergestreiften Muskels ähnlich ist: der absteigende Theil derselben erstreckt sich über ein sehr viel grösseres Abseissenstück, als der aufsteigende, und schliesst sich der Abseisse asymptotisch an. Die Zeitdauer der Curven beträgt mindestens 30 Secunden; sie kann sich aber auf eine Minute und mehr verlängern.

Die Pausen zwischen den einzelnen Zusammenziehungen sind sehr wechselnd, von 2-3 Minuten bis 15 Minuten.

In manchen Versuchen sind die aufeinanderfolgenden Curven von nahezu gleicher Höhe und Gestalt, ebenso ihre Intervalle nahezu gleich (Fig. 2). Meistentheils aber schwanken im Verlaufe derselben Beobachtung Form, Höhe und Frequenz der Zusammenziehung erheblich (Fig. 4). Unmittelbar nach der Präparation pflegt die Frequenz grösser zu sein, allmählich zu sinken.

In einzelnen Fällen verläuft die Zusammenziehung nicht continuirlich, sondern in Absätzen, die ihren Ausdruck in kleineren, über die Curve hinlaufenden Wellen finden (Fig. 3,4). Sie treten bald in kleinerer, bald in grösserer Zahl auf, 2-5 und mehr. Diese zusammengesetzten Curven haben meist eine grössere Zeitdauer, als die einfachen.

Die Anregung zu diesen spontanen Contractionen geht von 
dem hintern Ganglion aus; denn sie verschwinden nach dessen Exstirpation. Indessen will ich nicht unerwähnt lassen, dass ich bẹi einer mit $12 \mathrm{ccm}$ Morphiumlösung narcotisirten Muschel auch noch nach Ausrottung des Ganglions Contractionen gesehen habe. Was in diesem Falle den Anlass zur Reizung des Muskels gegeben, ob die Ueberfluthung mit Wasser oder mit Morphium, kann ich nicht sagen. Vielleicht war ein kleines Stück des Ganglions stehen geblieben. Jedenfalls lässt die iberaus grosse Mehrzahl meiner Beobachtungen keinen Zweifel, dass von dem Ganglion periodische Bewegungsimpulse für den Muskel ausgehen.

Wenn zwischen zwei Impulsen nicht ausreichende Zeit verfliesst, um den Muskel nach seiner Zusammenziehung sich wieder maximal ausdehnen zu lassen, so bleibt derselbe in grösserem oder geringerem Grade dauernd verkürzt: die Verkürzung steigt nach jedem Impulse and nimmt in den Pausen zwischen je zwei Erregungen wieder ab. Der gewöhnlichen physiologischen Ausdrucksweise folgend könnte man sagen, der Muskel besitze einen Tonus von periodisch wechselnder Stärke. Die tonische Contraction setzt hier nicht eine andauernde Erregung Seitens des Ganglions voraus, sondern sie wird durch einzelne, in Intervallen erfolgende Erregungen unterhalten. Je grösser das Intervall zwischen zwei Erregungen, desto mebr sinkt der Tonus in der Pause.

Von dem Mantel aus lassen sich jederzeit reflectorische Zusammenziehungen des Muskels erzielen, vermittelt durch das Ganglion, welches somit nicht bloss als automatisches (periodisch thätiges), sondern auch als reflectorisches Centrum fungirt.

Anders als an morphisirten Muscheln verbält sich unser Präparat, wenn es nicht narcotisirten Thieren entnommen ist. Nach vollendeter Anfertigung bleibt der Muskel im Zustande nahezu maximaler Zusammenziehung; der Zeichenhebel schreibt nur äusserst kleine, rhythmische Bewegungen der Schaale an. Diese Contraction kann mehrere Tage andauern; wir haben sie in einem Falle fünf Tage währen sehen.

Nach Exstirpation des Ganglions tritt Erschlaffung ein, aber der Tonus weicht nur ausserordentlich langsam, so dass Stunden vergehen können, bis die Erschlaffung eine vollständige ist. Ueber die Art, wie sie erfolgt, wird unten in $\S 6$ ausführlicher gehandelt werden. 
§3. Der vordere Schliessmuskel und seine Ganglien.

Wenn man von dem vordern Schliessmuskel ein ähnliches Präparat herrichtet, wie von dem hintern, indem man ihn in Zusammenhang mit den zugebörigen Schaalenstïcken nebst Schlossband und den beiden vordern Ganglien lässt, fällt von vornherein ein Unterschied des Verhaltens gegentiber dem des hintern Schliessmuskels auf: der letztere hielt die Schaale dauernd geschlossen, so lange er sich im Besitze seines Ganglions befindet, der erstere lässt sie zeitweise sich öffnen.

Diese Verschiedenheit könnte auf der Natur der beiden Muskeln selbst oder der mit ihnen verbundenen gangliösen Apparate beruhen. Es wäre denkbar, dass das hintere Ganglion auf seinen Muskel nur im Sinne der Zusammenziehung, die vordern Ganglien auf den Muskel nicht bloss im Sinne der Contraction, sondern auch im Sinne der Erschlaffung zu wirken vermöchten. Da nun aber bei der intacten Muschel eine Schaalenöffnung nur bei gleichzeitiger Erschlaffung beider Schliessmuskeln möglich ist, würde die Erschlaffung des hintern Muskels ebenfalls von den vordern Ganglien aus vermittelst des Verbindungsnerven eingeleitet werden müssen.

In der That, fertigt man ein Präparat des hintern Schliessmuskels in der oben beschriebenen Weise an, aber so, dass dasselbe durch die Verbindungsnerven in Zusammenhang mit der vordern Hälfte des Thieres bleibt, so sind jetzt die Erseheinungen wesentlich andere, als nach Trennung jener Nerven. Fig. 23 illustrirt das Verhalten. Der hintere Muskel macht eine Reihe von Zusammenziehungen; auf jede folgt eine mit beschleunigter Geschwindigkeit fortschreitende Erschlaffung. Die Verlängerungen werden allmählich bedeutender als die Verkürzungen, so dass der Muskel in hohem Grade ersehlafft. Bei dem Zeichen + wurden die Verbindungsnerven durchschnitten: jetzt stellt sich die tonische Contraction des Schliessmuskels wieder her, indem er sich wiederholt zusammenzieht, aber nach jeder Verkürzung sich nur verhältnissmässig wenig wieder verlängert. Der Unterschied der Gestalt der Contractionscurven vor und nach der Durchschneidung der Verbindungsnerven verdient eingehende Beachtung. Vor der Durchschneidung fällt jede Curve, nachdem sie ihr Maximum erreicht hat, concav nach der Abscisse hin ab, bis sie bei einer 
neuen Znsammenziehung plötzlich wieder steil ansteigt. Nach der Durchschneidung zeigt einen ähnlichen Verlauf nur der Anfangstheil der ersten Curve. Bei den spätern Curven wendet sich der absteigende Schenkel sehr bald convex zur Abscisse und nähert sich derselben überaus langsam. Diese augenfällige Verschiedenheit wird nur dadurch erklärlich, dass von dem hintern Ganglion aus dem Muskel Impulse zugeführt werden, welche Verkiirzung hervorrufen, von den vordern Ganglien aus aber demselben nicht bloss Erregungen zufliessen, welche ihn zur Verkürzung, sondern auch solche, welche ihn zur Erschlaffung veranlassen. Dass diese beiden in entgegengesetztem Sinne wirksamen Erregungen durch zwei verschiedene Classen von Nervenfasern vermittelt werden, sei hier vorläufig als Hypothese vorangestellt, für welche im Laufe der Untersuchung die Beweise beigebracht werden sollen.

Reizung der von den vordern Ganglien ausgehenden erschlaffenden Fasern scheint durch Dyspnoe herbeigefuhrt zu werden. Wenn man die obere Schaale in ihrer Mitte durch einen bis zum Schlossbande reichenden Querschlitz in zwei Hälften theilt, um die Zustände des hintern Muskels unabhängig von denen des vordern beobachten zu können, so öffnet sich ausserhalb des Wassers die hintere Schaalenbälfte jedesmal in kurzer Zeit; sie schliesst sich wieder, wenn man das Thier in das Wasser zuriekbringt.

Wenn nun die mitgetheilten Beobachtungen mit Wahrscheinlichkeit darthun, dass von den vordern Ganglien durch die Verbindungsnerven zum hintern Schliessmuskel theils solche Fasern gehen, deren Erregung ihn in Thätigkeit, theils solche, deren Erregung ihn ausser Thätigkeit versetzt, so wurde es nunmehr Aufgabe, jene beiden in den Verbindungsnerven enthaltenen Faserklassen genauer zu studiren.

\section{\$ 4. Versuche an den Verbindungsnerven.}

Bei allen folgenden Beobachtungen wurde das oben beschriebene Präparat des hintern Schliessmuskels verwandt, an welchem ein möglichst langes Stück der Verbindungsnerven geblieben war, zu dem Zwecke, an demselben Reizversuche anstellen zu können. Zur Reizung dienten constante Ströme, deren Stärke und Dauer je nach Umständen wechselte. Von eingängiger Untersuchung rein neurophysiologischer Fragen, wie z. B. des Erregungsgesetzes 
des Muschelnerven, mussten wir wegen Zeitbeschränkung absehen, da unser nächstes Ziel nur die Beibringung von Beweisen für die Existenz besonderer, den Muskel erschlaffender Nerven war.

Im Allgemeinen, doch nicht ausnahmslos, folgt auf eine wirksame Reizung der Verbindungsnerven zuerst eine Verkïrzung des Muskels. An dieselbe schliesst sich nicht immer Wiederverlängerung. Wo sie eintritt, ist sie unter bestimmten Bedingungen nur sehr gering und langsam, unter andern Bedingungen dagegen sehr erheblich, bedeutender als die voraufgehende Verkürzung, und schnell. Im ersteren Falle bleibt nach erfolgter Verkürzung der Muskel im Zustande stärkerer tonischer Contraction, als vor derselben, wenn auch der Tonus sich allmählich ein wenig verringert; im zweiten Falle verlängert der Muskel sich nach erfolgter Contraction schnell über seine urspringliche Länge, sein Tonus nimmt also ab, es tritt mehr oder weniger hochgradige Erschlaffung ein.

$\mathrm{Ob}$ das Eine oder das Andere geschieht, hängt allerdings einerseits von den unbekannten innern Zuständen des Nerven- und Muskelapparates ab, welche man unter der Bezeichnung ihrer Erregbarkeit zusammenfasst. Andererseits aber baben Stärke und Daner der zur Nervenreizung verwandten Ströme einen entscheidenden Einfluss. Trotz mannigfacher, nicht zu umgehender, weil in der verschiedenen Erregbarkeit der verschiedenen Präparate begrïndeter Schwankungen lässt sich etwa Folgendes sagen:

1. Zur Hervorrufung merklicher Zusammenziehung bedarf es eines Stromschlusses von nicht zu geringer Dauer. Bei schwächeren Strömen ist oft eine einmalige Schliessung von $1 / 8$ Sec. noch unwirksam. Wiederholung solcher unwirksamen Stromschliessungen in nicht zu langen Intervallen kann zu einer Wirkung führen, wo die einzelne Stromsehliessung dieselbe versagt. Die Pause zwischen den einzelnen Schliessungen kann, wenn eine solche Summationswirkung eintreten soll, je nach der Stromstärke bis zu 5 Sec. steigen. Bei Intervallen von 10 See. und mehr haben wir keinen Effect mehr erzielt. Man vergleiche hierzu Fig. 7.

2. Im Allgemeinen steigt bei gleicher Stromdauer die Grösse der Zusammenziehung mit der Stromstärke (vgl. Fig. 8). Doch ist die Abhängigkeit keine so entschiedene, wie bei den motorischen Nerven quergestreifter Muskeln.

3. Lässt man mehrere wirksame kurze Stromschliessungen in Pausen von 2 Sec. und mehr auf einander folgen, so steigt die 
Curve treppenartig an. Jede spätere Stufe der Treppe ist niedriger als die frühere, bis die Zusammenziehung eine gewisse Höhe erreicht hat. Von da ab treten in der der Abscisse nahezu parallel gehenden Curve nur noch kleine Undulationen anf (vgl. Fig. 9).

Sind die Reizungspausen kürzer, so entspricht nicht mehr jedem Einzelreize eine Einzelcontraction: die Zahl der Treppenstufen wird geringer als die Zabl der Reize (vgl. Fig. 11).

An die Zusammenziehung als in der Regel erste Folge der Reizung der Verbindungsnerven schliesst sich nun, wie bereits oben bemerkt, unter Umständen eine schnelle Wiederverlängerung und zwar über diejenige Länge, welche der Muskel vor der Verkürzung besass. Während in Versuchen, wie sie die Curven 8-11 zeigen, nach der Verkïrzung eine tonische Contraction des Muskels zuriuckbleibt, wird in den jetzt zu besprechenden Versuchen nach der Verkürzung der Tonus des Muskels herabgesetzt, d. h. es tritt Erschlaffung ein.

1. Am leichtesten erbält man diese secundäre Erschlaffung, wenn man nicht zu kurze Stromschliessungen (1 See.) in ebenfalls nicht zu kurzen Intervallen $(1 \mathrm{Sec}$ ) anf einander folgen lässt. In Curve 12 z. B. fallen auf die Zeiteinheit der Abscisse (15 Sec.) bei $a 8$ Stromschliessungen, durch 7 Pausen getrennt: der Erfolg: ist nach anfänglicher geringer Zusammenziehung eine iiberaus starke Erschlaffung. Als darauf Stromschliessungen derselben Stärke und Dauer in grössern Intervallen angewandt wurden, stieg die Curve treppenartig an und blieb nach jeder Verkürzung auf constanter Höhe. Die Pausen zwischen den Einzelscbliessungen können mitunter bis auf 15 Sec. verlängert werden, ohne dass die erschlaffende Wirkung ausbleibt (vgl. Curve 14 und 15: bei $a$ einzelne, bei $b$ mehrere Stromschliessungen).

2. Während eine einzelne kürzere Schliessung nur Verkürzung herbeiführt, kann längere Schliessung desselben Stromes secundäre Erschlaffung zur Folge haben. Man vergleiche in Fig. 13 die Wirkung der kutrzeren Schliessungen bei $\alpha$ mit dem Erfolg der längeren Schliessungen bei $b$.

3. Wenn eine längere Stromschliessung keine stärkere Erschlaffung herbeiführt, kann man dieselbe oft erzielen, wenn man in derselben Zeit, welche jene Schliessung in Anspruch nahm, mehrere kürzere Schliessungen auf einander folgen lässt. In Curve 
16 wird der Nerv bei a 30 Sec. durchströmt, der Muskel dehnt sich nach der Verkürzung nur ungefähr bis zu der ursprïnglichen Länge aus. Bei $b$ wird der Strom innerhalb 30 Sec. fiunfzehn Mal je 1 Sec. hindurch geschlossen: die Folge ist erheblich stärkere Erschlaffung.

4. Primäre Verlängerung ohne merkliche voraufgehende Verkürzung tritt nicht selten bei chemischer Reizung der Verbindungsnerven (Koclsalz in Lösung oder in Krystallen, Glycerin etc.) auf. Ein derartiges Beispiel wird später gegeben werden.

Es ist oben erwähnt worden, dass ein frisch angefertigtes Präparat des hintern Schliessmuskels mit seinem Nervenapparat, wenn sich selbst überlassen, sehr lange, oft Tage hindurch, in nahezu maximal contrahirtem Zustande verharrt: der Muskel befindet sich, um den Ausdruck der allgemeinen Muskelphysiologie zu brauchen, im Zustande eines hochentwickelten Tonus. . Durch passende Reizung des Verbindungsnerven, wie sie eben besprochen worden ist, lässt sich diese tonische Contraction mindern und beseitigen. Mitunter genügt schon einmalige Reizung durch einige secundenlange, in gleichen Pausen (von 1 Sec.) erfolgende Stromschliessungen, um Verlängerung des Muskels herbeizuführen, welehe nach wenigen Wiederholungen der Reizung in Intervallen von 2-3 Minuten wächst, so dass 10-15 Minuten ansreichen, um maximale Oeffnung der Schaalen herbeizuführen. In andern Fällen schwindet der Tonus schwieriger; es bedarf zur Herstellung vollständiger Atonie des Muskels zehnmaliger und noch bäufigerer Reizung. Die ersten Reizungen haben dann scheinbar gar keine, die nächsten geringe Wirkung, die mit der Zahl der Reizungen mehr und mehr wächst. In extremen Fällen kann bis zu maximaler Erschlaffung eine Stunde und mehr vergehen.

So iiberaus langsam weicht der Tonus namentlich dann, wenn die mit sensibeln Reizungen unvermeidlich verknüpfte Herstellung des Präparates lange dauerte, so dass sehr starke reflectorische Einwirkung auf den Muskel stattfand.

Ist der Muskel erst ein Mal erschlafft gewesen und dann (auf eine der später zu besprechenden Methoden) wieder in den contrahirten Zustand zurïckgefübrt, so erschlafft er zum zweiten Male unter Einwirkung der gleichen Reize auf den Verbindungsnerven viel leichter als das erste Mal.

In der Periode fortschreitender schneller Erschlaffung treten 
mitunter spontane Muskelcontractionen von eigenthümlichem Charakter auf, sehr abweichend von denjenigen, welche man beobachtet, wenn der erschlaffte Muskel in den Zustand tonischer Contraction zurückkehrt. In Curve 17 z. B. wird der Nerv durch eine Stromschliessung von 15 Sec. (bei a) gereizt: es tritt eine Schliessungsund eine kleinere Oeffnungscontraction auf. Unmittelbar darauf erschlafft der Muskel mit beschleunigter Geschwindigkeit. Seine Wiederverlängerung aber wird durch spontane Zusammenziehungen (bei $b$ ) unterbrochen, deren Curve im absteigenden Schenkel wiederum concav zur Abscisse verläuft. Bei dem erschlaffenden Muskel hebt also eine einzelne Zusammenziehung, auch wenn sie kräftig ist, die Atonie nicht auf, der zusammengezogene Muskel bleibt nicht zusammengezogen, sondern erschlafft schnell von Neuem. Ueber die Ursache der spontanen Zusammenziehungen sind bestimmte Aussagen nicht möglich.

Ganz anders als die während der Periode der vorschreitenden Erschlaffung auftretenden Contraktionscurven fallen solche ans, welche in dem Zeitraume der Wiederherstellung des Tonus aufgezeichnet werden. Ist nämlich der Muskel durch passende Reizung des Verbindungsnerven in hochgradige Erschlaffung versetzt worden, so kebrt der Tonus im Laufe der Zeit von selbst wieder zurück, oft noch an mehrere Tage alten Präparaten. Bei der Wiederherstellung des Tonus steigt die Curve nur selten continuirlich an. Meist wird das Ansteigen durch Contractionen unterbrochen, auf welche aber keine Wiederverlängerung folgt, so dass die Curve ein treppenartiges Aussehen gewinnt: jeder Zusammenziehung entspricht eine Treppenstufe. In Curve 18 z. B. wird durch mehrmalige Reizung der Verbindungsnerven (bei a) mittelst einer Folge von Stromschliessungen der Muskel hochgradig erschlafft. Bald darauf verkürzt er sich (bei $b$ ), ohne sich wieder zu verlängern, und solcher Verkürzungen folgen mehrere anf einander, bis der ursprüngliche Zustand nahezu wieder erreicht ist. Wiederholung (Vgl. $a$ und $b$ ) führt zu demselben Ergebnisse. Die aufsteigende Treppe ist in diesem Curvenbeispiele wenig regelmässig; in andern Fällen gestaltet sie sich viel regelmässiger, z. B. in Curve 19, wo bei $a$ durch Reizungen der Verbindungsnerven Erschlaffung berbeigeführt wird, welche der Zeit zweier Trommelumgänge bedarf, um sich in einer treppenartigen Curve wieder auszugleichen. - Aehnliche Treppencurven, wie sie hier bei spontaner Wiederherstellung 
des Tonus auftreten, lassen sich beliebig durch gewisse, später unten zu besprechende Erregungsweisen herstellen.

Die obigen beiden Curvenbeispiele zeigen, dass die zur Wiederherstellung des Tonus erforderliche Zeit sehr verschieden sein kann. In Curve 19 ist sie sehr viel länger, als in Curve 18.

§5. Die Ersehlaffung des Muskels bei Reizung der Verbindungsnerven rührt nicht von Ermiidung desselben her.

Die Reihe der bisher vorgelegten Beobachtungen hat zu folgenden Ergebnissen geführt.

Der hintere Schliessmuskel, wenn in Verbindung mit dem hintern Ganglion, aber ansser Verbindung mit den vordern Ganglien, befindet sich in der Regel in einem Zustande tonischer Contraction, welche sehr lange, oft Tage lang anbält.

Nach Excision des Ganglions schwindet der Tonus allmählich, aber überaus langsam.

Steht dagegen der Muskel noch durch die Verbindungsnerven in Zusammenhang mit den vordern Ganglien, so tritt zeitweise schnelle Erschlaffung des Muskels ein.

Dasselbe ist der Fall bei gewissen Reizungsweisen der Verbindungsnerven. Der Erschlaffung geht hier meist - doch nicht immer - eine Zusammenziehung des Muskels voraus. Wo sie vorhanden, könnte man in der Erschlaffung eine Folge von Ermüdung des Muskels durch die voraufgehende Contraction sehen.

Gegen die letztere Deutung spricht aber eine grosse Reihe von Thatsachen.

Zunächst: das sich selbst überlassene Präparat bleibt ermüdungslos Tage lang im Zustande maximaler Verkïrzung. Angesichts dieser Ausdauer ist es im höchsten Grade unwahrscheinlich, dass eine durch Reizung des Verbindungsnerven eingeleitete vorïbergehende und oft sehr unbedeutende Verkïrzung eine so hochgradige Ermiddung herbeiführen sollte.

Sodann gelingt es, wie schon oben bemerkt, nicht selten, durch chemische Reizung des Verbindungsnerven Erschlaffung obne voraufgehende Zusammenziehung herbeizufübren.

Wäre ferner die Arbeitsleistung des Muskels bei der Zusammenziehnng ausreichender Grund für die nachfolgende Er- 
schlaffung, so miisste jede Verkürzung gleicher Grösse auch gleich grosse Erschlaffung herbeifiihren. Die Erfahrung lehrt, dass dies keineswegs der Fall ist. Denn erstens giebt es Reizungsweisen des Verbindungsnerven, bei welchen die Verkürzung des Muskels nicht von Erschlaffung gefolgt ist (vgl. $\$ 4$ und Curve 8-12).

Zweitens lässt sich durch Reizung des Mantels reflectorische Zusammenziehung des Muskels erzielen, an welche sich niemals Erschlaffung anschliesst, wenn die Zusammenziehung auch von derselben Grösse war, wie die durch Reizung des Verbindungsnerven erzeugte. Den grossen Unterschied des Einflusses, welchen beide Reizungen auf den Muskel ausibben, zeigt in schlagender Weise Fig. 20 und 21.

In Fig. 20 wird der Verbindungsnerv bei $a$ durch eine Reihe von Stromschliessungen gereizt: anf eine geringe Contraction folgt erhebliche Erschlaffung. Bei $b$ Reizung des Mantels durch einzelne Schliessungen: jedesmal Zusammenziehung ohne Erschlaffung. Jede Contraction steigert den Tonus des Muskels. Den Unterschied des Reizerfolges bei diesem Versuche könnte man davon ableiten wollen, dass der Verbindungsnerv durch eine Reihe von Stromschliessungen, der Mantel jedes Mal dureh eine einzelne Stromschliessung gereizt würde. Aber in dem in Fig. 21 dargestellten Versuche geschahen beide Reizungen in gleicher Weise durch eine Reihe von Schliessungen, die Wirkungen sind trotzdem ganz verschieden: die Reizung des Verbindungsnerven (a) setzt den Tonus herab, die Mantelreizung $(b)$ verstärkt denselben.

Man könnte noch den Einwand erheben, dass die sensibeln Fasern des Mantelnerven vielleicht mit peripherischen Endorganen ausgeriistet seien, welche die eigenartige Wirkung veranlassen. Um diesen Gedanken zu prifen, haben wir wiederholt das Stämmchen des Mantelnerven selbst gereizt. Die Präparation zur Isolation desselben ist nicht ohne Schwierigkeit. Man bricht das hintere Stuick der nach oben gekehrten Schaale bis zum Schliessmuskel fort, so dass dieser nach Entfernung der beiderseitigen Kiemen an seiner hintern und seiner Banchseite freigelegt ist. Dadurch werden zwei vom hintern Ganglion ausgehende und nach hinten stark divergirende Fäden sichtbar, die Mantelnerven der beiden Seiten. Bei ihrer ausserordentlichen Feinheit misslingt leicht schonende Isolation, doch ist sie uns einige Mal gegliuckt. Die Reizung des Stämmchens hat dann ganz dieselben Folgen, 
wie die Reizung des Mantels: sie führt (s. Fig. 22 bei $c$ ) zu Verkürzung mit nur äusserst geringer allmählicher Wiederverlängerung, während gleiche Reizung des Verbindungsnerven (bei $a$ ) das erste Mal gar keine, das zweite Mal geringe Verkürzung, beide Male erhebliche Verlängerung zur Folge hat.

Ganz wie durch Reizung des Mantels, so kann auch durch Reizung der Kiemen Verkürzung ohne nachfolgende Erschlaffung bewirkt werden.

Somit kann es als vollkommen sichergestellt gelten, dass die Reizung des Verbindungsnerven ganz andere Folgen für den hintern Schliessmuskel hat, als Reizung des Mantelnerven: hier Verkürzung mit dauernder Steigerung, dort Verkürzung mit nachfolgender Herabsetzung des Tonus oder auch letztere allein.

Es ist nicht ohne Interesse, dass der vordere Schliessmuskel durch die Verbindungsnerven in ganz anderer Weise beeinflusst wird, als der hintere Schliessmuskel: sein Tonus wird durch dieselben nicht herabgesetzt; Reizung des Verbindungsnerven wie des Mantels hat gleiche Folgen, nämlich bleibende Verkuirzung. Da aber, wenn das Thier seine Schaalen öffnet, mit dem hintern auch der vordere Muskel erschlafft, ergiebt sich, dass letzterer seine detonisirenden Fasern nicht aus dem Verbindungsnerven, sondern aus andrer Quelle beziehen muss. Da ferner für beide Muskeln gleichzeitige Erschlaffung stattindet, lässt sich vermuthen, dass für beide die detonisirenden Fasern aus demselben Centro stammen, nämlich aus den vordern Ganglien, welche dem vordern Muskel die detonisirenden Fasern auf dem Wege der kurzen, von ibnen zu dem Muskel gehenden Nerven, dem hintern auf dem längern Wege der Verbindungsnerven zuführen. Dass diese Voraussetzung richtig ist, wird im folgenden Paragraphen erwiesen werden.

\$6. Ueberden Angriffspunkt der Nervenfasern, welche die Erschlaffung der Schliessmuskeln herbeiführen.

Durch Reizung des Verbindungsnerven, so sahen wir, kann die tonisehe Contraction, in welcher der hintere Schliessmuskel nach Herstellung des von uns benutzten Präparates sich befindet, aufgehoben und der Muskel in den Zustand der Atomie übergeführt werden. Nach der heutigen Terminologie der Physiologie würde man die hierbei in Betracht kommenden Fasern der Verbindungsnerven als Hemmungsfasern bezeichnen miissen. 
Eine noch heute trotz manches Einspruches weit verbreitete Vorstellung nimmt an, dass hemmende Fasern nicht in directer Verbindung mit den Muskeln stehen, deren Thätigkeit sie verringern oder aufheben, sondern sich zunächst in Zusammenhang mit gangliösen Centren setzen, aus welchen die motorischen Fasern der betreffenden Muskeln entspringen. Dureb die Hemmungsfasern werde unmittelbar die Thätigkeit nicht der Muskeln, sondern der Centren unterdrïckt, von welchen jene ihre motorischen Impulse erhalten.

Wenn man diese Anschaunngsweise auf den Schliessmuskel anwenden will, so wird man voraussetzen miissen, dass das hintere Ganglion sein motorisches Centrum sei, und dass die Verbindungsnerven zwei Classen ron Fasern enthalten, von denen die eine die Aufgabe hat, die Thätigkeit jenes Centrums zu verstärken, die andere, sie zu schwächen oder zu nnterdruicken. - Bei dem Schliessmuskel liegen nun die Verhältnisse sehr günstig, um jene Auffassung auf ibre Brauchbarkeit zu prïfen. Denn während bei andern muskulösen Apparaten, bei welchen Hemmungsvorgänge zu beobachten sind (Herz, Darm, Blutgefässe) die -- nachgewiesenen oder doch vorausgesetzten - Ganglienvorrichtungen im Innern jener Ápparate selbst liegen, so dass sie nicht exstirpirt werden können, ohne den Zusammenhang aller Theile zu stören, hat das Ganglion des Schliessmuskels ausserhalb desselben an leicht zugänglicher Stelle seinen Sitz. Im Innern des Muskels habe ich auf Hunderten von Schnitten, die mit Carmin oder Hämatoxylin gefärbt worden waren, keine Ganglienzellen finden können.

Wenn nun die Hemmungs- oder, wie ich sie lieber nennen möchte, die detonisirenden Fasern dadurch Erschlaffung des Muskels herbeiführen, dass sie das motorische Ganglion desselben ausser Thätigkeit setzen, so muss vollends schnelle Erschlaffung eintreten, wenn das Ganglion exstirpirt wird. Dass dem nicht so sei, ist bereits oben in $\S 2$ erwäbnt worden. Hier ist der Ort, genauer auf die Folgen der Entfernung des Ganglions einzugehen. Geschieht sie, während der Muskel sich im Zustande vollständiger Contraction befindet, so dass die Schaalen vollkommen geschlossen sind, so bleibt der Schaalenschluss mitunter zunächst unverändert, der Muskel also contrahirt, begreiflicher Weise, denn die Exstirpation des Ganglions ist ohne mechanische Reizung, deren Wirkung 
voriibergehen muss, nicht ausführbar. In andern Fällen wird bald eine Dehnung des Muskels merklich, aber sie schreitet enorm langsam fort, so dass lange Zeit, mitunter Stunden, vergehen, ehe der Muskel seine maximale Länge erreicht. Vor uns liegt z. B. eine der Raumersparniss wegen nicht mit abgebildete Dehnungscurve vom 6. 11. 84, welche, bis der Muskel seine maximale Länge erreicht, sich über 5 Trommelumgänge des Baltzar'schen Kymographions erstreckt, obschon jeder Umgang 40 Minuten dauerte.

Ganz anders bei der Reizung des Verbindungsnerven, welche die Erschlaffung überaus viel schneller herbeiführt, als sie nach Ausrottung des Ganglions eintritt. Am Prägnantesten tritt der Untersehied in Versuchen hervor, wie sie in Curve 24 dargestellt sind. Die bei $a$ durch eine Reihe von Stromschliessungen herbeigeführte Reizung der Verbindungsnerven hat geringe Zusammenziehung und unmittelbar anschliessend maximale Erschlaffung zur Folge. Um den aufgehobenen Tonus wieder herzustellen, wird (bei $b$ ) der Mantel wiederholt mechanisch gereizt. Man sieht sehr deutlich, wie die nach jeder Zusammenziehung folgende Wiederverlängerung des Muskels mit der Zahl der Reizungen träger und träger wird, bis sich der Tonus in hohem Grade wiederhergestellt hat. Nun wird bei $c$ das Ganglion exstirpirt: die Dehnungscurve des Muskels fällt vollständig anders aus als nach Reizung des Verbindungsnerven: nach geringer anfänglicher Senkung nähert sie sich der Abscisse nur sehr allmählich, es tritt also nar eine überaus langsame Abnahme des Tonus ein ${ }^{1}$ ).

Aus derartigen vielfach wiederholten Beobachtungen ergiebt sich mit Nothwendigkeit der Schluss, dass die Reizung des Verbindungsnerven nicht dadureh Ersehlaffung des Maskels herbeiführt, dass sie das Ganglion ausser Function setzt. Die hier in Betracht kommenden Nervenfasern mitssen vielmehr direct auf den Muskel einwirken, indem sie durch ihre Thätigkeit in demselben einen Vorgang einleiten, weleher zu schneller Abnahme des Tonus führt ${ }^{2}$ ).

1) Bei + wurde der Zeichenhebel zufällig etwas verrückt.

2) Ueberlässt man den Muskel, wenn er nach Excision des Ganglions allmählich sich ausgedehnt hat, in einem feuchten Raum sich selbst, so kann es vorkommen, dass man ihn nach längerer Zeit wieder mehr oder weniger 
Wenn dieser Schluss richtig ist, so müssen die fraglichen Fasern auch noch jenseits des Ganglions, zwischen diesem und dem Muskel oder in letzterem selbst anzutreffen sein. Es galt, sie daselbst aufzusuchen.

Zunächst versuchten wir die electrische Reizung des ganzen Muskels, indem wir an seine beiden Enden halbkreisförmig umgebogene Platinelectroden legten. Es gelang, durch eine Folge kurz danernder (1 Sec.) Stromschliessungen ähnlich, wie bei der gleichen Reizung der Verbindungsnerven, Erschlaffung herbeizuführen, doch war sie in der Regel nicht so erheblich und trat nicht so schnell nach dem Schlusse der Reizung ein, wie bei der Nervenerregung. Einzelne Stromschliessungen von längerer Dauer (40-45 Sec.) verstärkten den Tonus. Bei diesen Versuchen ist in Betracht zu ziehen, dass gleichzeitig die Muskelsubstanz mit den intramusculären Nervenenden gereizt wird, was die Ergebnisse complicirter und die Beurtheilung schwieriger macht.

Einfachere Resultate erhält man, wenn man die von dem Ganglion aus in den Schliessmuskel eintretenden Nervenstämmchen an ihrer Eintrittsstelle in denselben direct reizt. Isoliren lassen sich dieselben freilich nicht, aber man kann zwei sehr feine und einander sehr genäherte Platindrähte als Electroden auf die Nerveneintrittsstelle aufsetzen. Wendet man dabei diejenigen Reizungsweisen an, welche von den Verbindungsnerven aus Erschlaffung bewirkten, so gelangt man hier zu dem gleichen Ergebnisse. Wir waren öfters im Stande, auf diese Weise den maximal ausgebildeten Tonus des Muskels in maximale Atonie umzuwandeln. Dass hierbei die unvermeidliche gleichzeitige Reizung der Muskelsubstanz an eng begrenzter Stelle keine Rolle spielt, beweist ein sehr einfacher Controlversuch. Werden nämlich dieselben Electroden auf die der Nerveneintrittsstelle gegenüber liegende Seite des Muskels gesetzt, so gelingt es nicht Erschlaffung herbeizuführen.

Die in den Muskel eintretenden Nervenfasern sind theils erregende, theils erschlaffende. Löwit ${ }^{1}$ ) ist es gelungen, durch

contrahirt findet. Die Bedingungen, unter welchen ohne Mithülfe des Gan. glions der Tonus sich wiederherstellt, haben wir nicht genauer untersucht. Die Fähigkeit dazu kann nach 2 Tagen noch vorhanden sein; meist schwindet sie früher.

1) Löwit, Beiträge zur Innervation des Herzens. Dies Archiv Bd. 29, S. 402 . 
Einwirkung gewisser Salze anf den Froschvagus die in ihm enthaltenen beschleunigenden und hemmenden Fasern functionell für die electrische Reizung zu isoliren. In Erinnerung an diese Versuche bepinselten wir die Nerveneintrittsstelle des hintern Schliessmuskels mit einer Lösung von 0,2\% salpetersaurem Kali und 0,6\% Kochsalz. Nach 10-15 Minuten führte die electrische Reizung schnelle und starke Verlängerung des Muskels herbei, obschon die ihn dehnenden Kräfte dadurch sehr verringert worden waren, dass er nach Entfernung des Schlossbandes und Ersatz desselben durch ein Messingeharnier nur mit einem sehr geringen Gewichte belastet wurde. Curve 25 und 26 geben Versuchsbeispiele der Art: in der ersteren geht der Erschlaffung eine mässige Zusammenziehung voraus, in der letzteren folgt die Erschlaffung unmittelbar auf die Reizung. - So beweisend diese Versuche für die Annahme erscheinen, dass die detonisirenden Nervenfasern direct auf die Muskeln einwirken, so schien immerhin eine isolirte Erregung jener ohne jede gleichzeitige Reizung der Muskelsubstanz zur völligen Sicherung wünschenswerth. Was sich am hintern Schliessmuskel nicht durchfuihren liess, war an dem vordern erreichbar. Denn die vordern Ganglien liegen diesem nicht unmittelbar an; sie senden ihm, freilich ïberaus feine, Nervenfädchen von beilänfig $8 \mathrm{~mm}$ Länge zu, welche sich in folgender Weise zur Reizung präpariren lassen. Die bei dem Versuche nach oben zu kehrende Schaale wird in einiger Entfernung von dem Vorderende der Muschel bis gegen das Schlossband, aber nicht bis ganz an dasselbe heran, vorsichtig abgebrochen. Ungefähr auf der Verbindungslinie des hintern und des vordern Muskels, in etwa $8 \mathrm{~mm}$ Entfernung von dem letzteren, schimmert durch den diinnen Mantel das Ganglion als kleiner gelber Körper hindurch. Nach vorsichtiger Zerreissung des Mantels über dem Ganglion präparirt man die aus $\mathrm{ihm}$ tretenden Nervehen in einer schmalen Brücke des sie umgebenden Gewebes nach dem Muskel hin frei, schnürt den Gewebsstrang mit einem feinen Faden von dem Ganglion ab und legt ihn auf passende Electroden. Das andersseitige Ganglion muss vor Beginn des Versuches exstirpirt werden.

Bei der Reizung des Nervchens zeigen sich nun dieselben Erscheinungen am vordern Muskel, wie bei Reizung der Verbindungsnerven am hintern Muskel. Einmalige kurze (1 Sec.) Stromschliessung steigert den Tonus, eine Folge solcher Schliessungen setzt 
ihn (nach vorgängiger Verkürzung) herab (Vgl. Curve 28). Dass es sich dabei nicht um Stromschleifen handelt, welche den Muskel selbst durehsetzen, kann vielfach dargethan werden. Unterbindung der Nerven zwischen den Electroden und dem Muskel hebt die Reizerfolge auf. Directe Reizung des Muskels auf der dem Nerveneintritt entgegengesetzten Seite führt keine Erschlaffung herbei.

Chemische Reizung (Kochsalzkrystall) des Nervenstämmchens ruft hier viel beständiger, als bei dem Verbindungsnerven, Erschlaffung des Muskels hervor, und zwar oft obne sichtbare primäre Zusammenziehung. Indess ist bezüglich des letzteren Punktès zu bedenken, dass das Schlossband einem schwachen Contractionsbestreben erheblichen Widerstand entgegensetzt. Um zu entscheiden, $o b$ die primäre Zusammenziehung wirklich vollständig fehle, wurde in einer Reihe von Versuchen das Schlossband dureh ein Messingcharnier ersetzt und der Schreibhebel nur schwach belastet (30 grm). Unter diesen Umständen wurde in der That mit wenigen Ausnahmen vor der Erschlaffung eine primäre Zusammenziehung sichtbar. Bei Behandlung der Nerven mit Salpeterlösung (S. oben) trat oft ohne Weiteres schnelle primäre Erschlaffung ein, wie sie z. B. Curve 29 zeigt.

Gegen die Beweiskraft des Versuches an dem Nervenstämmchen könnte noch etwa der Einwand erhoben werden, dass vielleicht im Verlaufe des Nerven zwischen dem grossen Ganglion und dem Muskel mikroscopische Ganglienzellen lägen, fähig den Tonus za unterhalten. Die mikroscopische Untersuchung ergiebt dafür keine Anhaltspunkte.

Ausserdem widerlegt jene Vermuthung der folgende Versuch: Nachdem das Präparat in der oben erörteten Weise hergestellt und der Nerv dicht an dem Ganglion durchschnitten worden ist, so dass er in Länge von ca. $8 \mathrm{~mm}$ mit dem Muskel in Verbindung steht, wird die überaus langsam sich senkende Dehnungscurve des Muskels gezeichnet. Nach einiger Zeit wird der Nerv unmittelbar an dem Maskel durch einen schnellen Scheerenschnitt getrennt: die Curve ändert aber ibren Verlauf nicht im Mindesten. Wären längs des Nerven „tonisirende“ Ganglienzellen vorhanden, so mïsste die Curve nach Abtrennung des Nerven schneller sinken als vorher, was eben nicht der Fall ist. 


\section{§. 7. Schlussbemerkungen.}

Die mitgetheilten Versuche führen auf ein schwieriges und bis jetzt dunkles Gebiet der allgemeinen Muskel- und Nervenphysiologie. Der unmittelbare Inhalt der Beobachtungen freilich ist klar, nicht so die Einreibung der berichteten Thatsachen unter die geläufigen Anschauungen der Wissenschaft.

Zu den Schliessmuskeln gehen zwei Classen von Nervenfasern, die einen motorische, welche Verkürzung des Muskels veranlassen, die andern, wie man heute wohl sagen würde, hemmende, welche den verkiirzten Zustand des Muskels aufheben und Erschlaffung desselben herbeifiihren. Die motorischen Nerven entspringen für jeden der beiden Muskeln aus dem zunächst gelegenen Ganglion; die hemmenden oder erschlaffenden Fasern gehen insgesammt aus den vordern Ganglien hervor. Sie werden dem vordern Schliessmuskel durch die kurzen, ihm von den vordern Ganglien zugesandten Nervenstämmeben, dem hintern Schliessmuskel durch die Verbindungsnerven zugeführt.

Das hintere Ganglion fungirt für den hintern Schliessmuskel als motorisches Centrum, die vordern Ganglien spielen dieselbe Rolle gegenïber dem vordern Sehliessmuskel. Die motorischen Zellen der beiderseitigen Ganglien können sowohl von peripherischen Nervenfasern (des Mantels, der Kiemen) als durch gewisse Fasern des Verbindungsnerven in Thätigkeit versetzt werden. Die vordern Ganglien sind überdies im Stande, in beiden Schliessmuskeln Erschlaffung herbeizuführen.

Die Schliessmuskeln können selbst nach ihrer Trennung von den zugehörigen Ganglien aus dem Zustande des Tonus in der der Erschlaffung übergehen und aus diesem in den Zustand des Tonts zurtickkehren. Aber beiderlei Veränderungen treten an den sich selbst überlassenen Muskeln überaus langsam ein und erfordern Stunden.

Schneller lässt sich der eine Zustand in den andern unter Vermittelung der Nerven herbeifuihren. Doch haben wir stets beobachtet, dass voll entwickelter Tonus auch bei passender Erregung der Nerven nur allmählich der Erschlaffung weicht; leichter ist schon die Umwandlung der Atonie in den Tonus, obschon auch hier meist erst wiederholte Nervenerregung vollständig zum Ziele führt. 
So weit ist alles klar und verständlich. Die Schwierigkeit liegt aber in der Definition der erschlaffenden Nerven und des Erschlaffungszustandes. Indess liegen doch bekannte Thatsachen vor, an welche die unsrigen sich anreihen.

Bei der Zusammenziehung und Erschlaffung des Schliessmuskels handelt es sich offenbar um denselben Vorgang, wie bei Verengerung und Erweiterung der Blutgefässe. Wenn man im Anschlusse an eine friberhin allgemein getheilte Auffassung der sogenannten Hemmungsvorgänge die Hypothese aufstellte, dass die Gefässe peripherische motorische Centra besässen, welche die Ringmuskulatur der Gefässe in tonische Thätigkeit versetzen, und dass die Verengerungsnerven diese Centra zu verstärkter Thätigkeit veranlassen, die Erweiterungsnerven ihre Action beschränken, so stützte sich diese Hypothese wohl hauptsächlich auf den histologischen Befund von Ganglienzellen in den Speicheldrüsen, an deren Gefässen bekanntlich durch Cl. Bernard die Entdeckung von Erweiterungsnerven gemacht wurde. Indess entzogen interessante Beobachtungen von M. von Frey ${ }^{1}$ ) jener Anschaung jede Wahrscheinlichkeit.

Wenn nämlich die Verengerungs- und die Erweiterungsnerven an demselben Punkte des motorisehen Mechanismus in entgegengesetztem Sinne angreifen, so muss wohl das Ergebniss einer gleichzeitigen Erregung beider Nervenclassen die algebraische Summe ihrer Einzelwirkungen sein, sofern jede Classe die Wirkung der andern unmittelbar beeinträchtigt. Aber in Wirklichkeit liegen die Dinge viel verwickelter. Denn von Frey sah bei gleichzeitiger maximaler Reizung des Sympathicus und der Chorda den Blutstrom in der Druisenvene ebenso stocken, wie bei Reizung des Sympathicus allein. Wenn aber die Doppelreizung aufgehoben wurde, beschleunigte der Strom sich ebenso, als ob die Chorda allein gereizt worden wäre. Wurde ferner zuerst die Chorda bis zu maximaler Beschleunigung des Blutstromes gereizt, dann nach Schluss dieser Reizung durch Sympathicus-Erregung der Strom zum Versiegen gebracht, so schwoll er nach Aufhebung der Sympathicus-Reizung wieder zu der durch die Chorda-Reizung be-

1) Max von Frey, über die Wirkungsweise der erschlaffenden Gefässnerven. Arbeiten aus der physiologischen Anstalt zu Leipzig, XI. Jahrgang 1876, Leipzig 1877, S. 89. 
dingten Höhe an. Diese und ähnliche Beobachtungen von Frey's beweisen, dass die Verengerungs- und die Erweiterungsnerven der Gefässe nicht in dem Sinne unmittelbar gegen einander wirken, dass die einen die durch die andern gesetzten Veränderungen verringerten oder riickgängig machten. Der Sympathicus vielmehr lässt die durch die Chorda hervorgernfenen Veränderungen der Gefässmosculatur fortbestehen. Er unterdrickt nur die Aeusserungen derselben. Beide Nerven mïssen demnach ibre Einwirkung offenbar auf versehiedene Theile des motorisehen Apparates der Gefässe richten.

Auf welche Theile aber, darïber geben jene wichtigen Untersuchungen keinen Aufschluss. Denkbar wäre vielerlei, z. B. dass die einen Nerven auf gangliöse Centra, die andern direct auf die Musculatur wirkten, oder anch, dass der Sympathicus die grössern in die Drïse eintretenden Arterien verengte, die Chorda die kleinern, die Capillaren speisenden Arterien erweiterte, u. s. f. Der Schliessmuskel der Anodonta ist nun ein ungleich gïnstigeres Object, um den nächsten Angriffspunkt der beiderlei Nervenclassen zu ermitteln. Da die von den Ganglien zu den Muskeln gehenden Nervenstämmchen beide Fasergattungen enthalten und im Innern der Muskeln Ganglienzellen nicht vorhanden sind, müssen sowohl die motorischen als die erschlaffenden F'asern direct auf die Muskelfasern selbst einwirken, - das ist ein nach unsern Beobachtungen unvermeidlicher Schluss.

Die Thatsachen drängen aber ferner zu der Annahme, dass das, was wir als Erschlaffung bezeichneten, nicht bloss Aufhebung derjenigen innern Veränderungen in der Muskelfaser ist, welche die Verkürzung bedingen, und dass der innere Vorgang der Verkürzung nicht ohne Weiteres diejenigen Veränderungen im Innern der Muskelfasern aufhebt, welche die Erschlaffung herstellen. Wäre dies der Fall, so dürfte der erschlaffte Muskel nach einmaliger Zusammenziehung nicht wieder in den erschlafften Zustand zurïcksinken. Aber Curven, wie z. B. No. 17, die wir durch viele ähnliche vermehren könnten, zeigen, dass die Verhältnisse anders liegen. Durch die Reizung $a$ wird der verkürzte Muskel nach kurzer Steigerung der Verkürzung erschlafft. Die spontanen Contractionen bei $b$ bringen ihn auf seinen ursprünglichen Verkürzungsgrad zurieck, aber er ist nicht, wie vor der Reizung $a$, im Stande; denselben längere Zeit zu erhalten, sondern er erschlafft 
nach jeder Contraction immer von Neuen, - grade wie die durch Chorda-Reizung erschlafften Speicheldrüsengefässe auch nach vorübergehender Verengerung (durch Sympathicus-Reizung) von Neuem sich erweitern. Es müssen also wohl besondere Theile im Innern der Muskelfasern sein, auf weichen die Verkürzung, und besondere, auf welchen das, was wir Erschlaffung nannten, beruht. -

Ueber die nähere Natur des letzteren Zustandes kann nach den bisherigen Erfahrungen vorläufig nichts Fruehtbares ausgesagt werden. Untersuchungen von Biedermann haben so viel gezeigt, dass der Muskel in erschlafftem Zustande bei directer electrischer Reizung sich ganz anders verbält, als im contrabirten Zustande. Für die genauere Kenntniss des ersehlafften Zustandes bedürfte es zunächst einer besonderen Untersuchung darüber, ob bei der mit der Reizung der erschlaffenden Nerven verbundenen Verlängerung des Muskels positive Arbeit geleistet werden kann, d. h. ob die Verlängerung auf activer Streckung beruhe. Grünhagen und Samkow ${ }^{1}$ ), welche den ausgeschnittenen Sphincter pupillae des Katzenauges bei directer electriseher Reinng sich verlängern sehen, schreiben demselben ein Vermögen der „Elongation" oder "activen Erschlaffung." zu. Aber der Sphincter war mit einem Zeichenhebel belastet, die Verlängerung bedeutet also vielleicht nur vergrösserte Dehnbarkeit, womit noch nicht der Beweis für die Befähigung zu positiver Arbeitsleistung während der Verlängerung gegeben ist. Soll der Ausdruck ,active Ersehlaffung" oder "active Verlängerung" zur sagen, dass dieselbe auf einer activen Einwirkung gewisser Nerven beruht, so ist dagegen Nichts einzuwenden. Der Beweis dafür, dass die Verlängerung auf einer Leistung der Muskeln berubt, bei welcher äussere Arbeit geleistet werden kann, - dieser Beweis steht aus.

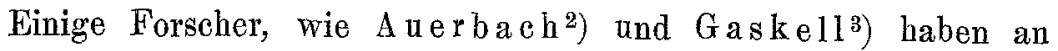
die Möglichkeit gedacht, dass die contractilen Faserzellen einerseits durch Contraction in der Längsrichtung sich zu verkürzen, andererseits durch Contraction in der Querrichtung sich zu ver-

1) Grünhagen und Samkowy: Ueber das Verhalten isolirter glatter Muskeln bei electrischer Reizung. Dies Archiv Bd. X, 165, 1875.

2) Tageblatt der Naturforscherversammlung zu Graz. 1875.

3) Gaske11, on the nature of vascular dilatation. Journal of anatomy and physiology XI, 7451877. 
längern im Stande seien. Die Richtigkeit dieser Hypothese vorausgesetzt, würde die Verlängerung in der That eine active Streckung sein. Aber es liegt doch eben nur eine Hypothese vor, uiber deren Richtigkeit die Zukunft zu entscheiden haben wird. Die Entscheidung aber wird theils durch eingehendere experimentelle Analyse der mechanischen Bedingungen des Erschlaffungsvorganges, theils durch Controlle des thermisehen Verhaltens des Muskels während seiner Verlängerung gesucht werden können. Leider machte es mir das Ende meines Aufenthaltes in Breslau unmöglich, die Untersuchung in der bezeichneten Richtung: weiter zu verfolgen.

\section{Erklärung der Curven anf Tafel I.}

Alle Curven sind von links nach rechts zu lesen. Die Vergrösserung der Contractionen durch den Schreibhebel ist für die ersten fünf Curven $1: 1,5$, für die Curven 28 und 29 beträgt sie 1:2, für alle übrigen 1:3. - Die Abscisseneinheiten sind für die Curven 1,5 und 6 gleich 1 Sec., für alle übrigen 15 Sec. - Auf der untern Horizontallinie sind die zur Reizung verwandten Stromschliessungen angegeben. Wenn letztere nur 1 Sec. davern und in Pausen gleicher Länge auf einander folgen, sieht man nur einzelne, nahe an einander gedrängte verticale Striche auf der Reizungslinie. - Die Ströme wurden in der Regel aus dem Kreise zweier Grove'scher Elemente mittelst des Rheochords abgezweigt. Bei den meisten Versuchen betrug der Rheochordwiderstand $100 \mathrm{~cm}$; Abweichungen davon sind besonders angegeben, ebenso, wenn statt der Grove'schen Elemente eine Zink-Kohle-Säule benutzt wurde.

Curve 1-5 stammen von dem hintern Schliessmuskel morphisirter Muscheln her, welcher in Verbindung mit seinem Ganglion gelassen war. Curve 1: Spontane Contraction. Curve 2: Regelmässig wiederkehrende einfache spontane Zusammenziehungen. Ourve 3 und 4: Zusammengesetzte spontane Wellen.

Curve 5: Reizung des Verbindungsnerven. 4 Zink-Kohle-Elemente.

Curve 6: Illustrirt die Unwirksamkeit kürzerer (a), die Wirksamkeit längerer (b) Stromschliessungen für den Verbindungsnerven. 2 Grove, ganzer Rbeochord.

Curve 7: Zeigt bei $x$, dass Reizungen, die einzeln unwirksam sind, durch Wiederholung in kürzeren Pausen wirksam werden können. 
Curve 8: Verschiedenheit der Wirkung verschieden starker Ströme. Bei $a 1 \mathrm{~cm}$, bei $b 50 \mathrm{~cm}$ Rheochord.

Die beiden Curven 7 und 8 stammen von demselben Präparate, von welchem Tags zuvor die Curve 6 gewonnen worden war.

Curve 9, 10 und 11: Steigerung des Tonus durch Stromschliessungen gleicher Stärke bei Verschiedenheit der Pausen.

Curve 12: Erschlaffung des Muskels bei Reizung (a) des Verbindungsnerven durch eine Folge von Stromschliessungen von je 1 Sec. Pausen von gleicher Daner. - Wiederherstellung des Tonus durch vereinzelte Reizungen (b) von gleicher Stärke und Dauer.

Curve 13: Reizung des Verbindungsnerven durch Stromschliessungen von 1 Sec. (a) und ron 5 Sec. (b).

Curve 14: Erschlaffung des Muskels bei Reizung des Verbindungsnerven dureh Summirung (b).

Curve 15: Ebenfalls Summation (b) der Reizungen.

Curve 16: Stromschliessungen von 30 Sec. (a) führen nicht Eirschlaffung herbei, wohl aber 15 Schliessungen von je 1 Sec. (b).

Curve 17: Spontane Contractionen während schnell fortschreitender Erschlaffung.

Curve 18: Erschlaffing durch Reizung (a) der Verbindungsnerven; spontane schnelle Wiederherstellung des Tonus.

Curve 19: Das obere Stïck der Curve ist hier die Fortsetzung des untern. Erschlaffung durch Reizung des Verbindungsnerven (a). Sehr allmähliche Wiederherstellung des Tonus; ansteigende Treppe.

Curve 20: Reizung des Verbindungsnerven (a) und des Mantels $(b)$.

Curve 21: Ebenso.

Curve 22: Bei $a$ Reizung des Verbindungsnerven, $b$ mechanische, $c$ electrische Reizung des Mantels.

Curve 23: Einwirkung der vordern Ganglien auf den hintern Schliessmuskel. Bei + Durchschneidung der Verbindungsnerven.

Curve 24. a Erschlaffung des hintern Schliessmuskels durch Reizung der Verbindungsnerven. $-b$ successive Wiederherstellung des Tonus durch mechanische Reizung des Mantels. - $c$ Exstirpation des hintern Ganglions.

Curve 25: Reizung (a) der Eintrittsstelle des Nerven in den hintern Schliessmuskel.

Curve 26: Ebanso. Erschlaffung ohne voraufgehende Contraction.

Curve 27: Reizung (bei a) der Nerveneintrittsstelle am vordern Schliessmuskel.

Curve 28: Reizung (a) des Nerven des vordern Muskels zwischen diesem und dem Ganglion.

Curve 29: Chemische Reizung des Nerven. Bei + wird auf denselben eine Lösung von salpeters. Kali $(0,25 \%)$ und Kochsalz $(0,6 \%)$ aufgetragen. 


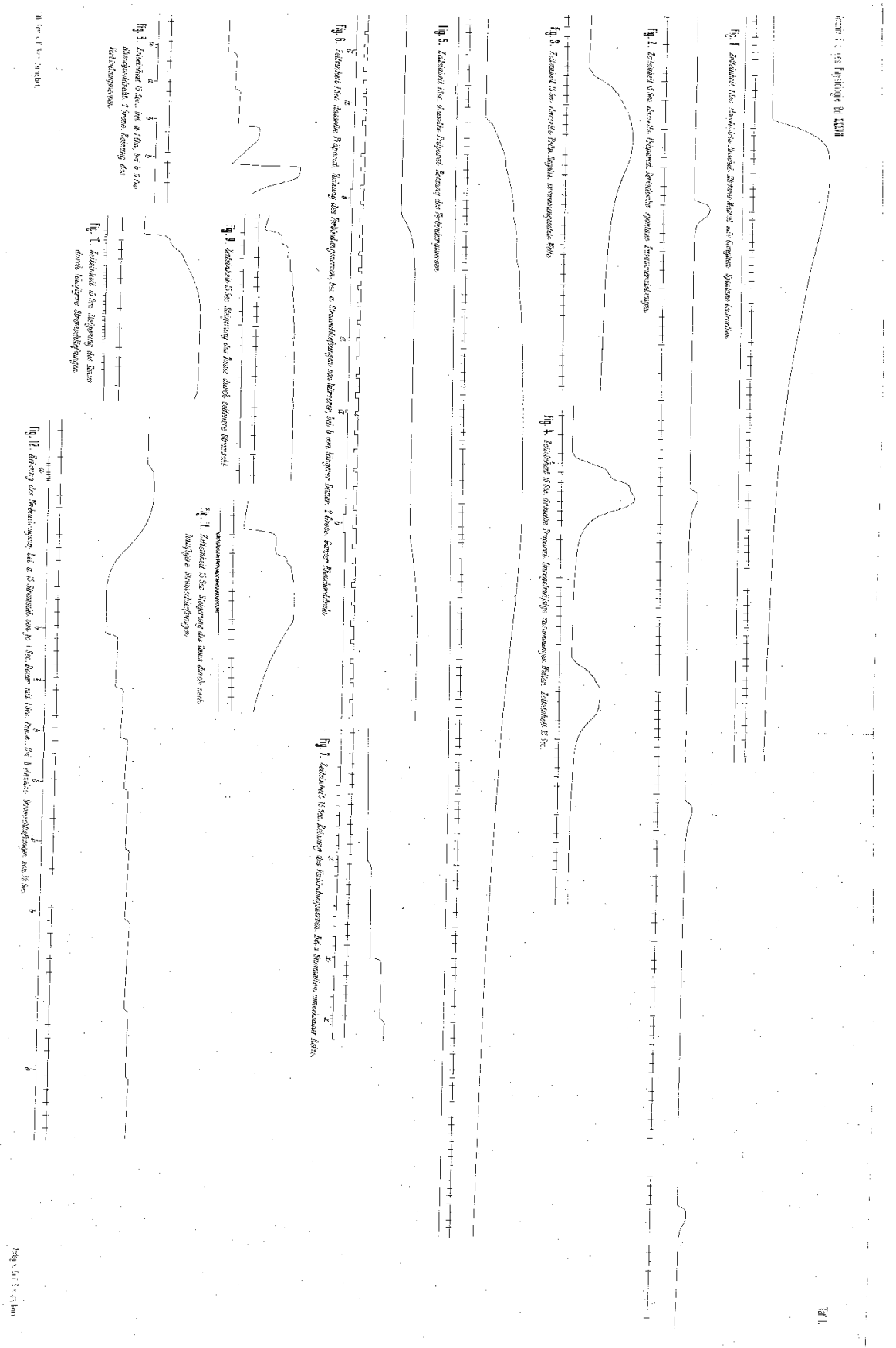




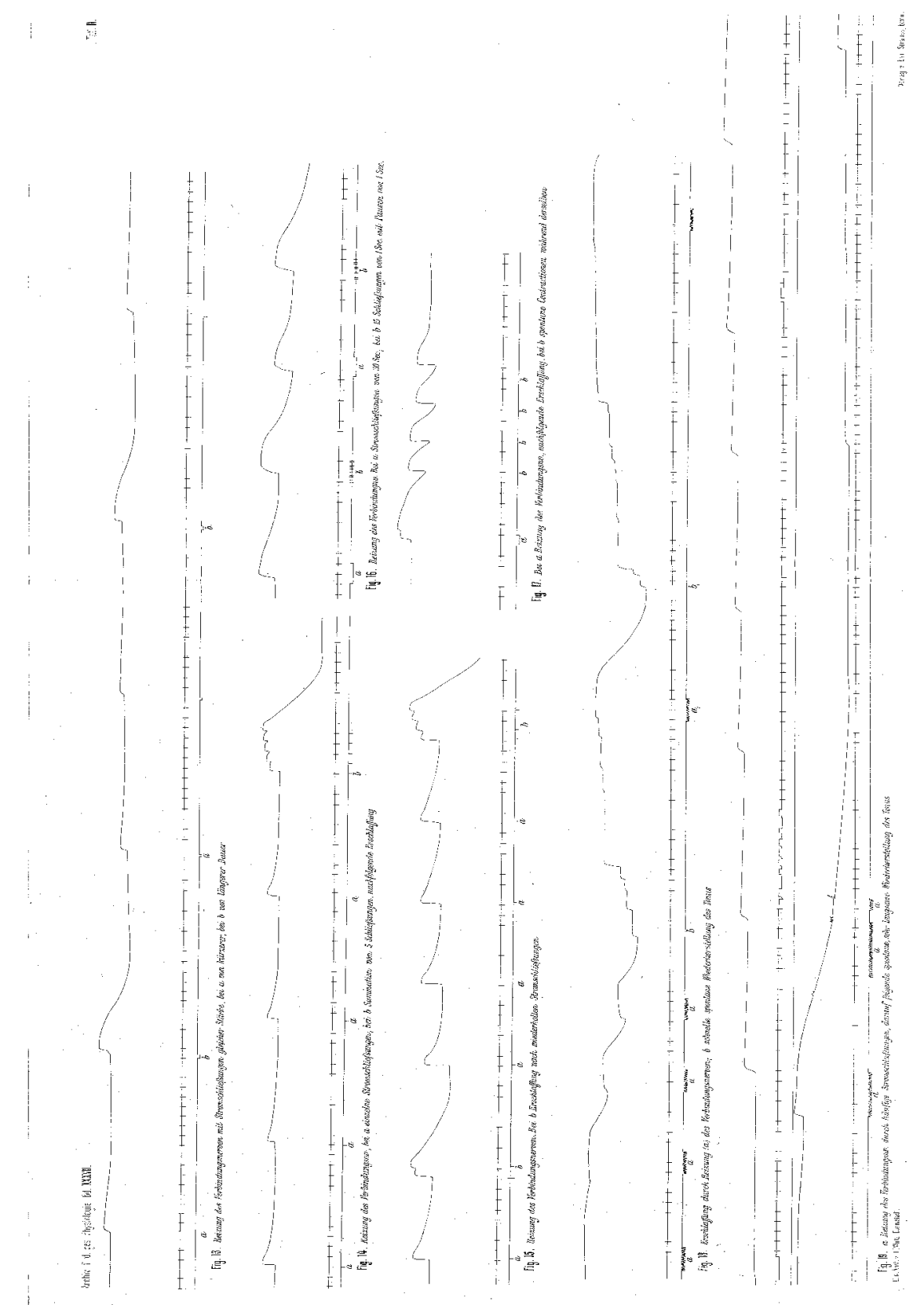




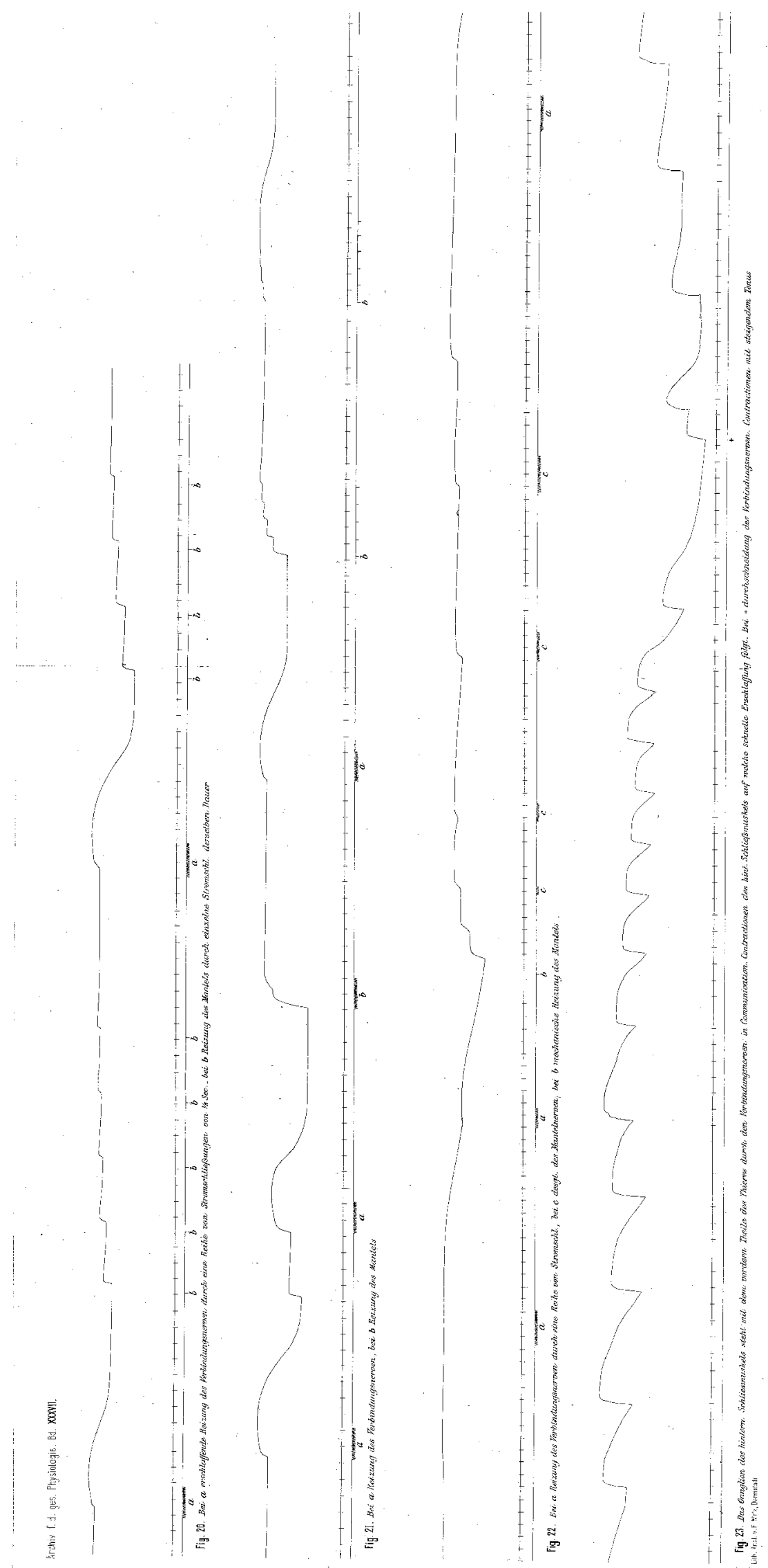




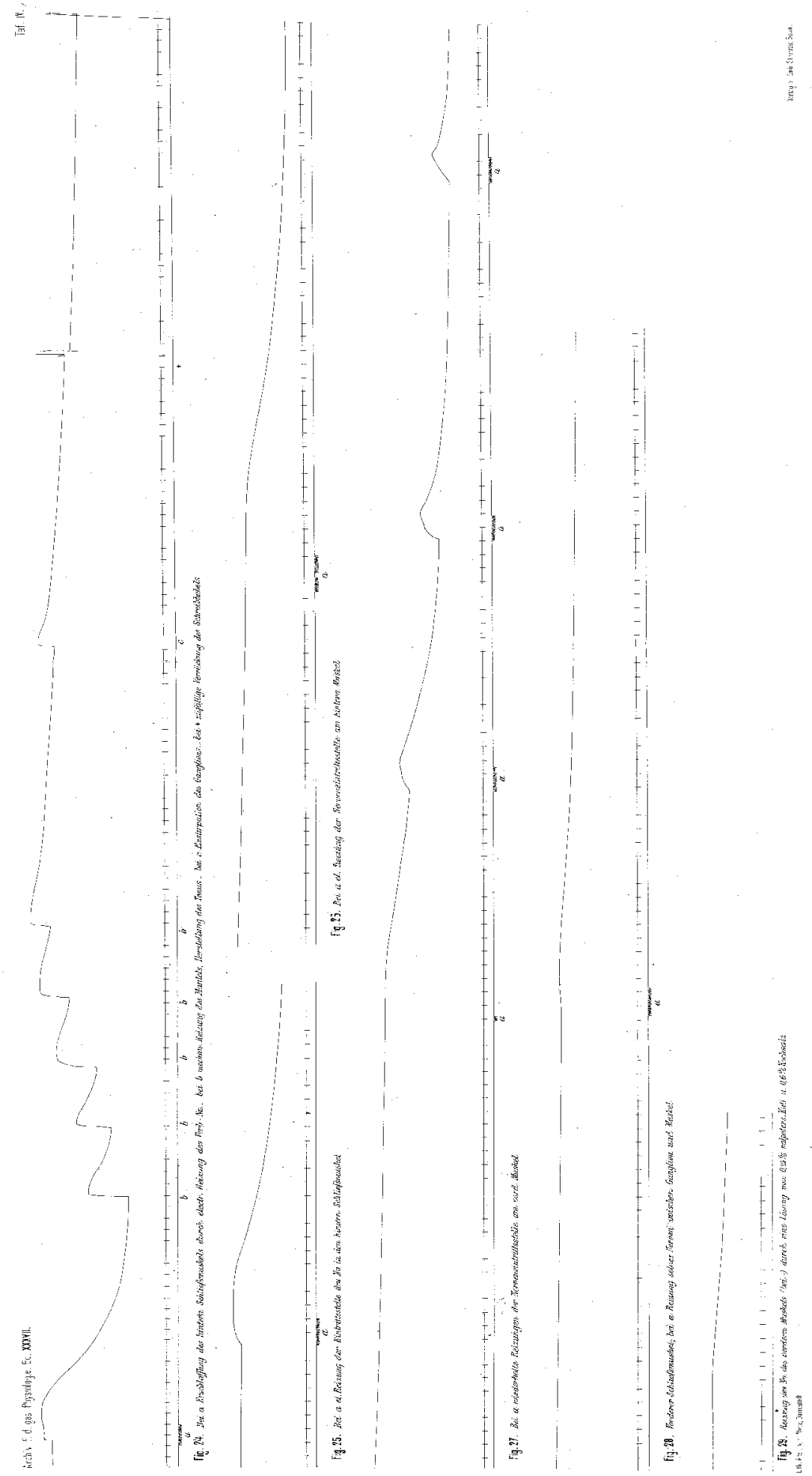

